\title{
CDISC SEND Vital Signs Test Name Terminology
}

National Cancer Institute

\section{Source}

National Cancer Institute. CDISC SEND Vital Signs Test Name Terminology. NCI

Thesaurus. Code C120537.

Terminology associated with the vital signs test name codelist of the Clinical Data

Interchange Standards Consortium (CDISC) Standard for the Exchange of Non-clinical Data (SEND). 